\title{
Anatomical Study of the LarynxIn Indigenous Male Turkey (Meleagris gallopava)
}

\author{
A. M. AL-Mussawy \\ N. H. AL-Mehanna \\ E. F. AL-Baghdady \\ Coll. of Vet.Med./ Unive. Of Al- Qadisiya
}

\begin{abstract}
The study aim to explain the anatomical description of the larynx in the indigenous male turkey (Meleagris gallopava). For making use as a basic information in the study of the respiratory physiology, histopathology, the respiratory diseases diagnosis, and surgery and anesthesia of turkey. Five healthy birds (first year of age and weighing (4715 $\pm 43.3 \mathrm{gm})$ ) employed in this study. After well bleeding, the larynx detected, and then the shape, position, dimensions of each specimen and its components were recorded. The larynx appeared as a heart-shaped mound in the caudal part of the oropharyngeal cavity. It consisted of a single hyaline cricoid cartilage which consisted of body and left and right wings, double hyaline arytenoid cartilages which consisting of body and rostral and caudal processes, and single hyaline procricoid cartilage which consisted of body dorsally and tail ventrally. Also there were superficial and deep intrinsic and rostral, caudolateral, and caudomedial extrinsic laryngeal skeletal muscles.
\end{abstract}

\section{Introduction}

The anatomy, physiology, and mechanics of avian respiratory system are distinctly different from that of mammals, and it is has principal function of exchanging oxygen and carbon dioxide between atmosphere and blood, involved in temperature regulation, and phonation where these features in common with the respiratory system of mammals $(1,2)$. The difference where in the absence of epiglottis, and in the larynx which does not have vocal cords, therefore is not involved in voice production and (3).Laryngeal mound (mons laryngealis) in the chicken, turkey (Meleagris gallopava), and longlegged buzzard (Buteo rufinus), appears as a conspicuous elevation carrying the opening (inlet or glottis). It is heart-shaped, directed rostrally, from the base of the skull into a transverse mucosal folds at the base of the tongue, protrudes into the caudal part of the floor of the oropharynx (4, 4, and 6). Whereas laryngeal mound is roughly triangular in shape in the West African guinea fowl (Numida meleagris galeata) (7), in ostriches the larynx protrudes from the pharynx and have not laryngeal mound (8). The inlet (glottis) of the larynx of the domestic fowl (Gallus gallus var. domesticus), and of the ostriches appear as slit-like opening limited by the arytenoid cartilages, and continuous caudally by narrow groove called the laryngeal fissure (sulcus larynges) (8,9, 10).In birds like the chicken and long legged buzzard, each side of the laryngeal mound bears four rows of caudally pointing cornifide papillae which appear as a large rostral and short caudal transverse row and there are two sagittal rows of 5-6 small papillae found on the lateral and medial borders of the caudal arytenoid process. $(4,6,11)$ while in ostriches the papillae are not visualize (8).

The Laryngeal Skeleton consists from two single and one paired cartilage, further to the laryngeal ligament and muscles.

The cricoid cartilage in avian is single and hyaline in type which consists of three components. The median body which is large, gutter-like plate, concave dorsally, rostral shovel-shape expansion from it cartilaginous and flexible, and a median ossified ridge projection dorsally in the body of cricoid cartilage, the left, and right wings which united with the lateral part of the body by a thin line of flexible cartilage. The medial border of each wing articulates with the procricoid cartilage forming procricocricoid synovial joint. (12, 13),In songbirds, passerine species (Corvus corax, $C$. orru, and C. brachyrhynchos) the 
cricoid wings are separate as dorsal cricoid cartilages, and rod like cartilages, $(4,9)$.

In turkeys, the cricoid cartilage is much shorter than that in the chicken rostrocaudally, and is ending rostrally at the level of the rostral tip of the arytenoid cartilages (11).

The procricoid cartilage is a single and hyaline in type in chicken, turkey, nonpasserine species (spheniscids, Gallus, and Columba ), passerine species (several Corvids), and long-legged buzzard. It appear as comma-shaped flattened dorsoventrally cartilage, intervenes between the two arytenoid cartilages, and between the two cricoid wings. Laterally and dorsally the body has facets which articulate with the bodies of the left and right arytenoid cartilages, form the procricoarytenoid synovial joints. The tail has left and right facets which articulate with the left and right cricoid wings (6, 9, and 11).

The arytenoid cartilage is a paired and hyaline in type in chicken, duck, turkey and long-legged buzzard they meet together dorsocaudally and form the roof of the larynx and margins of the glottis. It consists of the body, the rostral process extends to the oral end of cricoid cartilage, and the caudal process is free end and course dorsally. $(6,9)$. Baumel, et. al. (9) says that the arytenoids caudal process variable or absent in ratites and penguins.

There are two laryngeal ligaments in the larynx of birds, the aryteno-cricoid and the aryteno- arytenoid ligaments. In spheniscids, Gallus, Columba, and stix the

\section{Materials and methods}

Five healthy male turkeys were used; the mean live weight was $(4715 \pm 43.3$ gm). Specimen were prepared by bleeding of birds with the cutting of the major neck blood vessels after making an skin incision in the neck and separation of trachea away from the site of cutting to avoid aspiration of blood and spoiling of the respiratory system.Each specimen of larynx observed immediately after prepared, described the position in situ and shape registered, then carefully removed, and fine dissections rostral process, body of arytenoid cartilage and body and wings of cricoid cartilage are held together by the aryteno-cricoid ligament $(9,11)$. In Corvids, this ligament is continued caudally between arytenoid body and the dorsal cricoid cartilage therefore named aryteno-cricoid dorsalis ligament (9). The Aryteno-arytenoid ligament (intraarytenoid ligament) in chicken and Corvus brachyrhynchos (passerine species) is connected between the right and the left arytenoid cartilages of the body and the caudal process $(9,11)$.

There are two types of the laryngeal muscles - intrinsic and the extrinsic.

Generally in birds the intrinsic laryngeal muscles are the superficial muscles which run from the wing and the body of cricoid cartilage to the arytenoid cartilage. The deep muscle horse-shoes-shape comprises three division medial, middle, and lateral. It runs from caudal midline of the larynx to the cricoid and arytenoids cartilages $(6,9)$. Whereas in chicken and bursa roller pigeon (Columba livia), the extrinsic laryngeal muscles are, rostral extrinsic muscles are paired muscle extend from the dorsal surface of the rostral basibrachial bone of the hyoid rostrally to the larynx caudally, The caudolateral extrinsic muscle is paired muscle arise from composite tracheal muscle and mainly inserted into the dorsal mass and into the body and wing of cricoid cartilage, and the caudomedial extrinsic muscle is unpaired muscle which arise from composite tracheal muscle and insert onto the ventral surface of the cricoid body. $(9,11)$.

immediately.The weights of laryngeal mound, dimensions of the laryngeal components, length and width of laryngeal glottis and length of the dorsal laryngeal fissure. The objective of the present study is intended to describe anatomical features of the larynx in details, as to be a basic data for respiratory physiological, and histopathological studies, and for in surgery and anesthesia in this species of birds. 


\section{Results}

The laryngeal mound in the male turkey in this study appeared as obvious elevation, elongated heart-shaped. It was lie on the floor of the oropharynx, and extended from the base of the tongue rostrally to the first tracheal ring and esophageal entrance caudally (Fig. 1). The weight of the larynx ratio to the life birds weight ratio was $(0.048 \%)$. The laryngeal glottis occurred on the median of the laryngeal mound, limited by laryngeal arytenoid cartilages, the mean length and width of the glottis were $(1.15 \pm 0.05 \mathrm{~cm})$ and $(0.22 \pm 0.00 \mathrm{~cm})$ respectively. It was continued caudally by $(0.7 \pm 0.07 \mathrm{~cm})$ laryngeal fissure (Fig. 1).One group of long cornefied caudally pointing laryngeal papillae was seen on the caudal end of the laryngeal mound contained one left and one right long. Also, there was 1-2 small caudal direction papillae dangled on the lateral aspect of the preceding papillae, and other groups of papillae appeared as short rostral and caudal transverse rows papillae, parallel with each other, taking caudomedial orientation (Fig. 1).The skeleton of the larynx seen consisted from the single cricoid and procricoid cartilage, the paired arytenoid cartilages, the external and internal muscles, and the ligaments:-

The Cricoid cartilage found as unpaired, hyaline cartilage, constituted the basal part of the larynx. It consisted of three parts:The body of the cricoid cartilage was the greatest, gutter-like plate short extending rostrally, had ventral (convex) and dorsal (concave) surfaces. In the median of dorsal surface of the cricoid cartilage, there was median mucosal ridge. (Fig. 2). The left and right cricoid wings have caudal border contained medial facet to articulate with the lateral facet of the tail of the procricoid cartilage forming the procricocricoid synovial joint. The rostral borders of the wings were thicker than the caudal border. The ventral and dorsal part of the wings united by a thin line of flexible cartilage (Fig. 2).The procricoid cartilage: - was found at the caudal portion of the larynx as unpaired, median short-tack shape hyaline cartilage, consisted of body dorsally and tail ventrally. The body contained right and left dorsolateral facets to articulate with the bodies of arytenoid cartilages at the right and left ventromedial facets forming procricoarytenoid synovial joint (Fig. 3).

The arytenoid cartilages: - Appeared as left and right hyaline cartilages meeting together caudally, acting as ceiling of the larynx and limiting of the glottis, each one consisting of body which appeared in the lateral view as channel-like restricted by the dorsal and ventral borders and contained ventromedial facet at the caudal part to articulate with procricoid cartilage, rostral process extended parallel with the rostral extending of the cricoid cartilage. The caudal process which enveloped by group one of laryngeal papillae (Fig. 4).

The laryngeal Muscles consist from two intrinsic and three extrinsic groups of muscles. The Superficial intrinsic muscles found as paired muscles lie under the mucosa of the dorsal surface of the laryngeal mound, gave the laryngeal mound appearance. They arose from flexible cartilage thin line which united the ventral and dorsal part of the cricoid cartilage and inserted along the dorsal border of the arytenoid cartilage (Fig. 5).

The deep intrinsic muscles found as paired muscles lie under the previous muscles and blended with it. They composed of three parts, medial, middle, and lateral which had a common origin from the caudal midline of the larynx by muscle fibers. (Fig. 5).

The Rostral extrinsic muscles were found as paired muscles, arose from the ventral surface of the cricoid body, and inserted in the rostral basibrachial bone of the hyoid bone (Fig. 6).

The caudolateral extrinsic muscles seen as paired muscles arose mainly from sternotrachealis muscle, and inserted on the lateral edge of the ventral surface of the body of the cricoid cartilage (Fig. 6).

The caudomedial extrinsic muscle: - was seen as paired muscles arose from the sternotrachealis muscle, and inserted on to 
the middle of the ventral surface of the cricoid cartilage body (Fig. 6).

Four Laryngeal ligaments were found; the aryteno-cricoid ligament was seen as a paired broad sheet connected the ventral border of the lateral channel of the arytenoid cartilage and rostral border of the cricoid cartilage wing (Fig. 7).

The aryteno-arytenoid ligament was appearing as small ligament connected the right and left arytenoid cartilages at the

caudal midline dorsal to the
procricoarytenoid synovial joints.

The aryteno-glossal ligament was seen as thick ligament attached the rostral processes of arytenoid cartilages and the paraglossal bone of the tongue (Fig. 7). And the crico-tracheal ligament was found as broad dorsally and narrow ventrally, connected the caudal border of the cricoid cartilage with the first tracheal ring (Fig. 7).

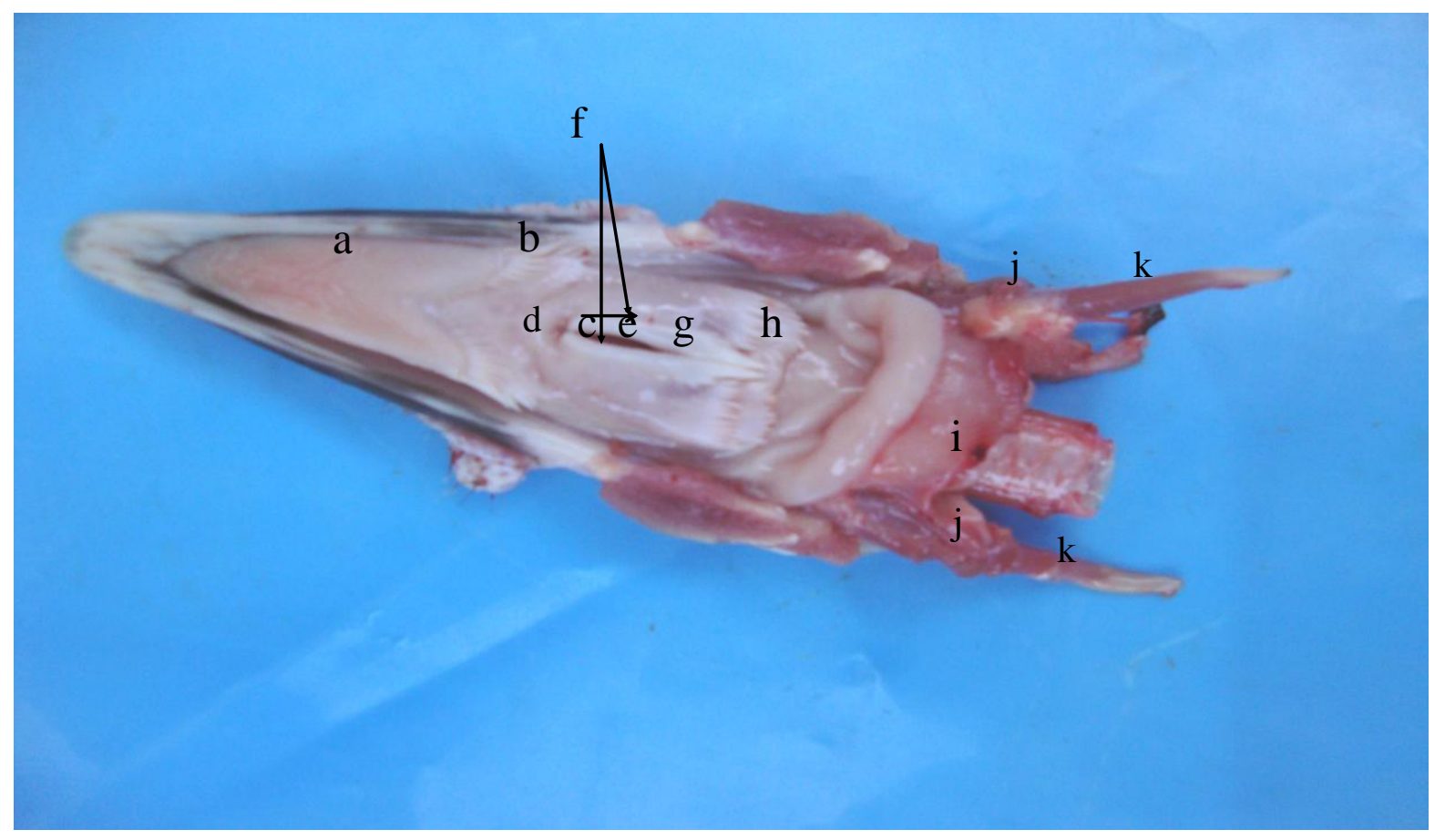

Fig. (1): Head of the male turkey after removal of cranium and upper beak, demonstrating the dorsal view of the floor of the oral cavity and pharynx with the esophageal entry: tongue (a) lingual papillae (b), laryngeal mound (c), laryngeal glottis (d), laryngeal fissure (e), arytenoid cartilages (f), laryngeal papillae (g), esophagus entrance (h), tracheal cartilages (i), ceratobtranchial bone of the hyoid bone (j), epibranchial bone of the hyoid bone $(\mathrm{k})$. 


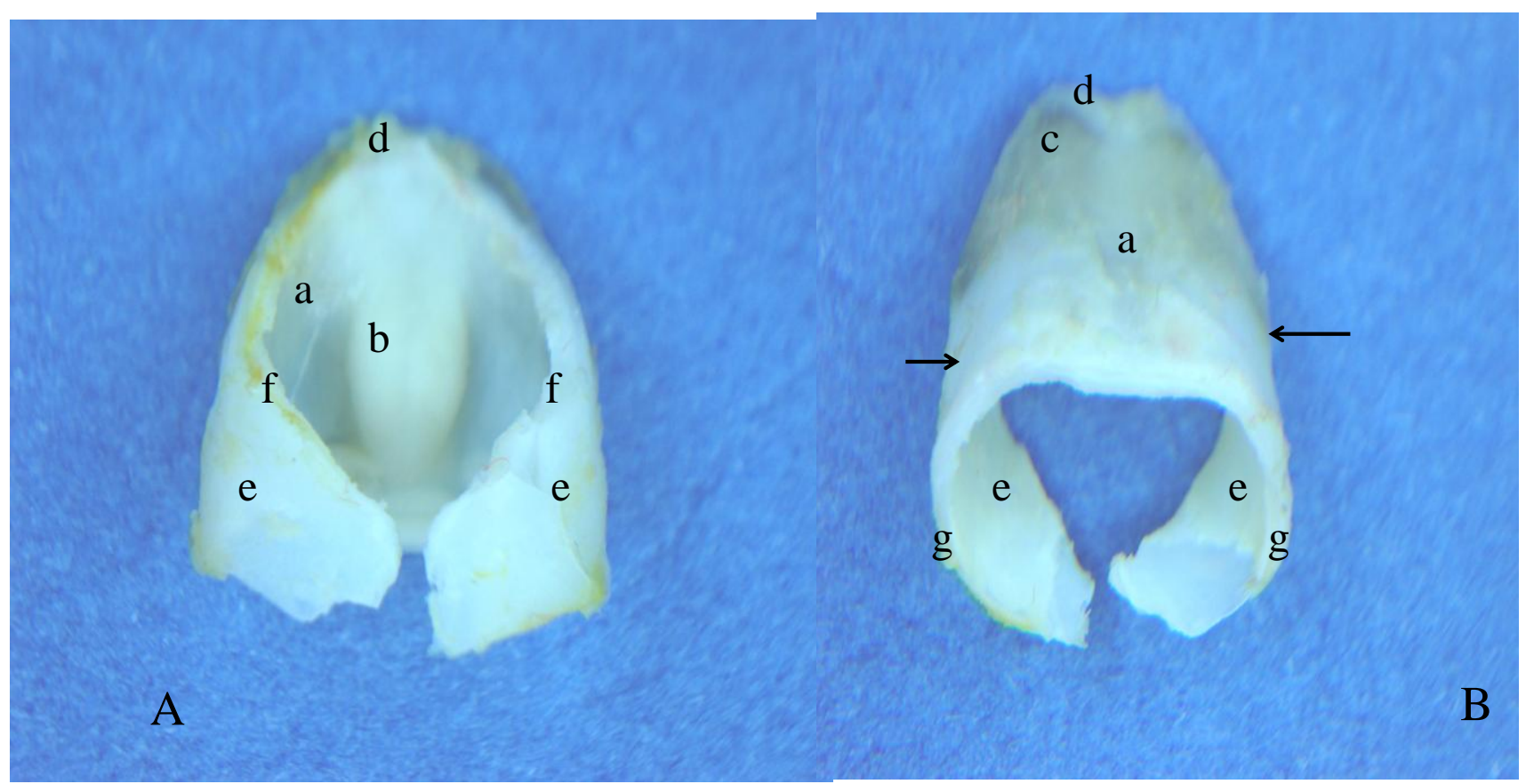

Fig. (2): Magnified cricoid cartilage of larynx of Turkey (dorsal (A) \& ventral (B) view) showing: cricoid body (a), median mucosal ridge of the criciod body (b), fully ossification of the ventral surface of the cricoid body (c), rostral extending of the cricoid body (d), cricoid wings (e), rostral borders of the cricoid wings (f), caudal borders of the cricoid wings $(\mathrm{g})$, thin line of flexible cartilage (arrow). (X 24)

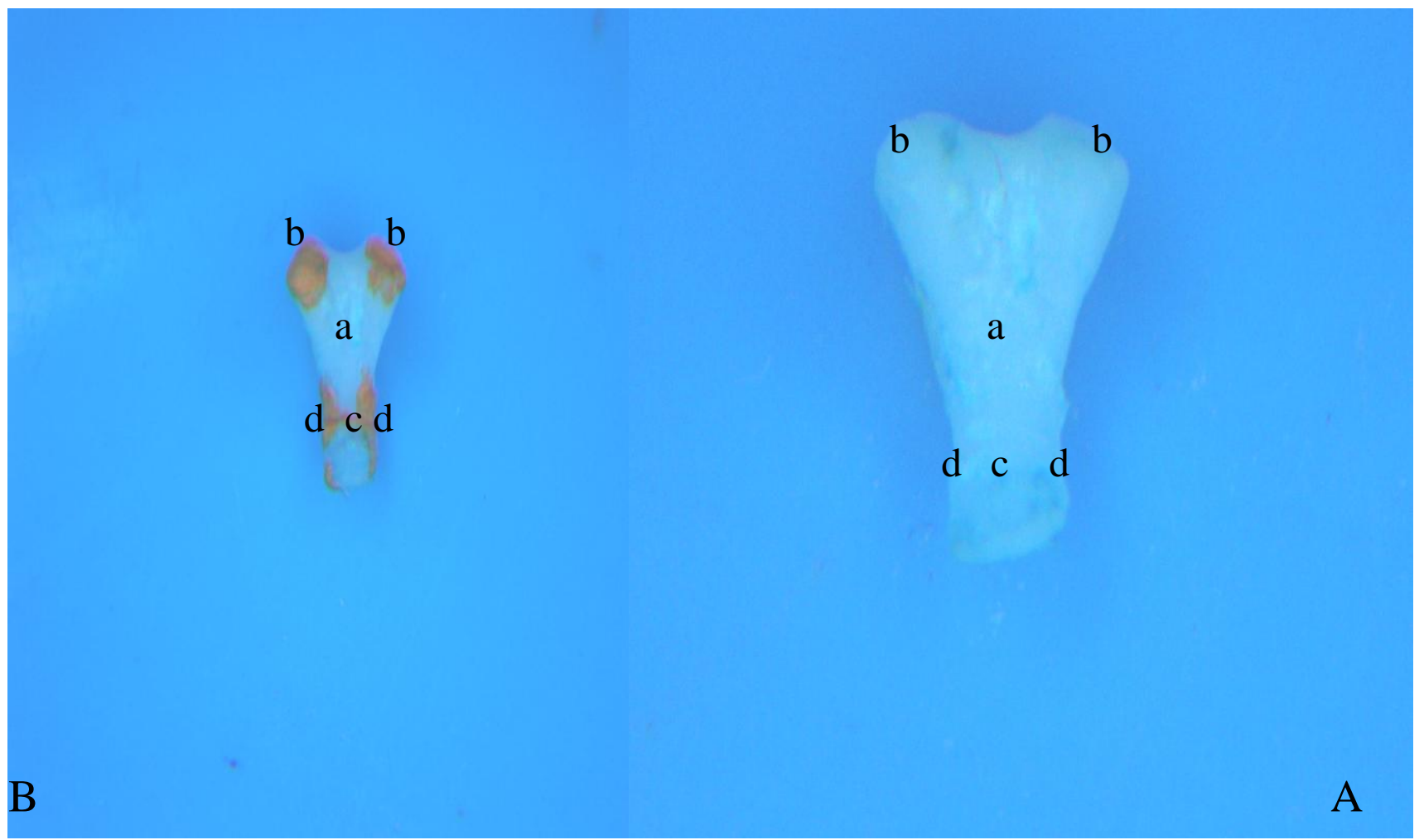

Fig. (3): Magnified procricoid cartilage of larynx of Turkey (caudal (A), caudal painted (B) view) showing: body of procricoid cartilage (a), dorsolateral articulation facets (b) tail of procricoid cartilage (c) caudolateral articulation facets (d). (X 24 A, X 12B). 


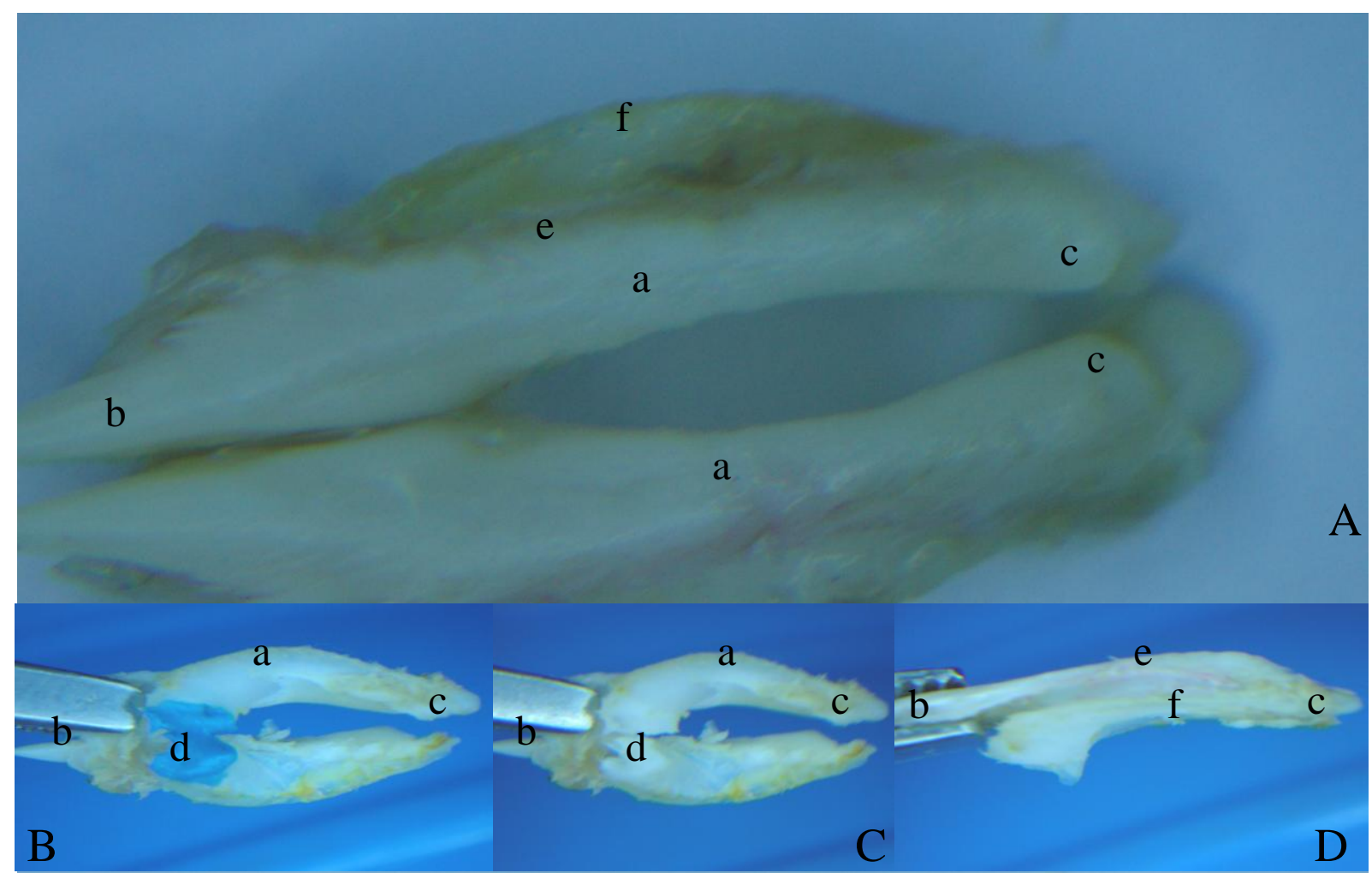

Fig. (4): Arytenoid cartilages of the larynx of the Turkey (dorsal (A), ventral (B\&C), and lateral (D) view) demonstrate: body of the arytenoid cartilage (a), rostral process (b), caudal process (c), ventromedial articulation facets (d), dorsal border (e), ventral border (f). (X 24 A, X 12 B, C, D).

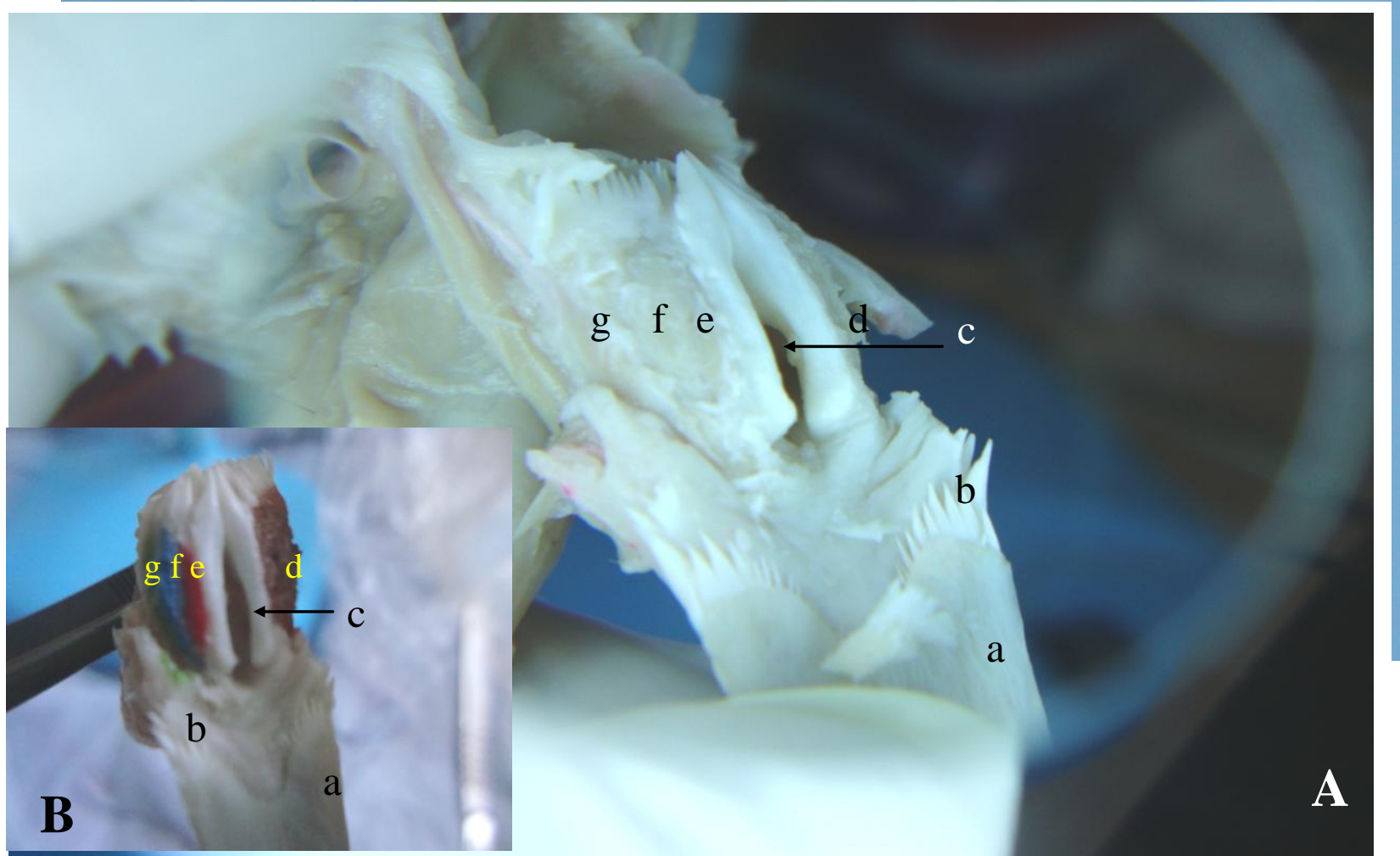

Fig. (5): Dorsal view of the intrinsic laryngeal muscles of turkey. ((A) muscles were painted by watery color, and (B) magnified view (zoom 12) showing: tongue (a), lingual papillae (b), laryngial glottis (c), superficial intrinsic muscle (d), medial part of the deep intrinsic laryngeal muscle (e) middle part of the deep intrinsic laryngeal muscle (f) lateral part of the deep intrinsic laryngeal muscle (g). 


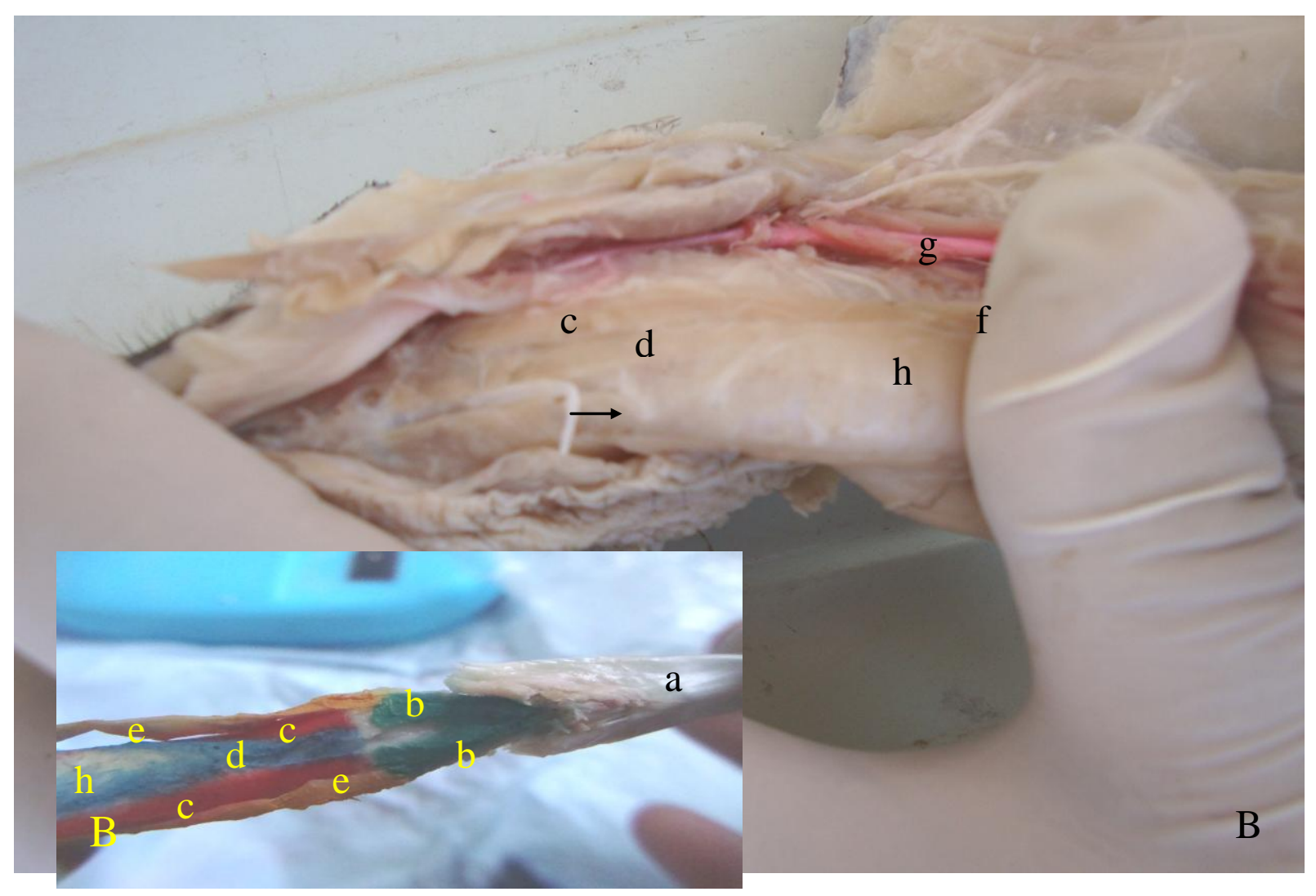

Fig. (6): Ventral view of the extrinsic laryngeal muscles of turkey. ((A) muscles were colored by watery color) showing: tongue (a), rostral extrinsic muscles (green) (b), caudolateral extrinsic muscles (red) (c), caudomedial extrinsic muscles (blue) (d), tracheolateral muscles (yellow) (e), sternotrachials muscles (f), common carotid artery (g), trachea (h), caudal basebranchial bone of the hyoid bone (arrow). 


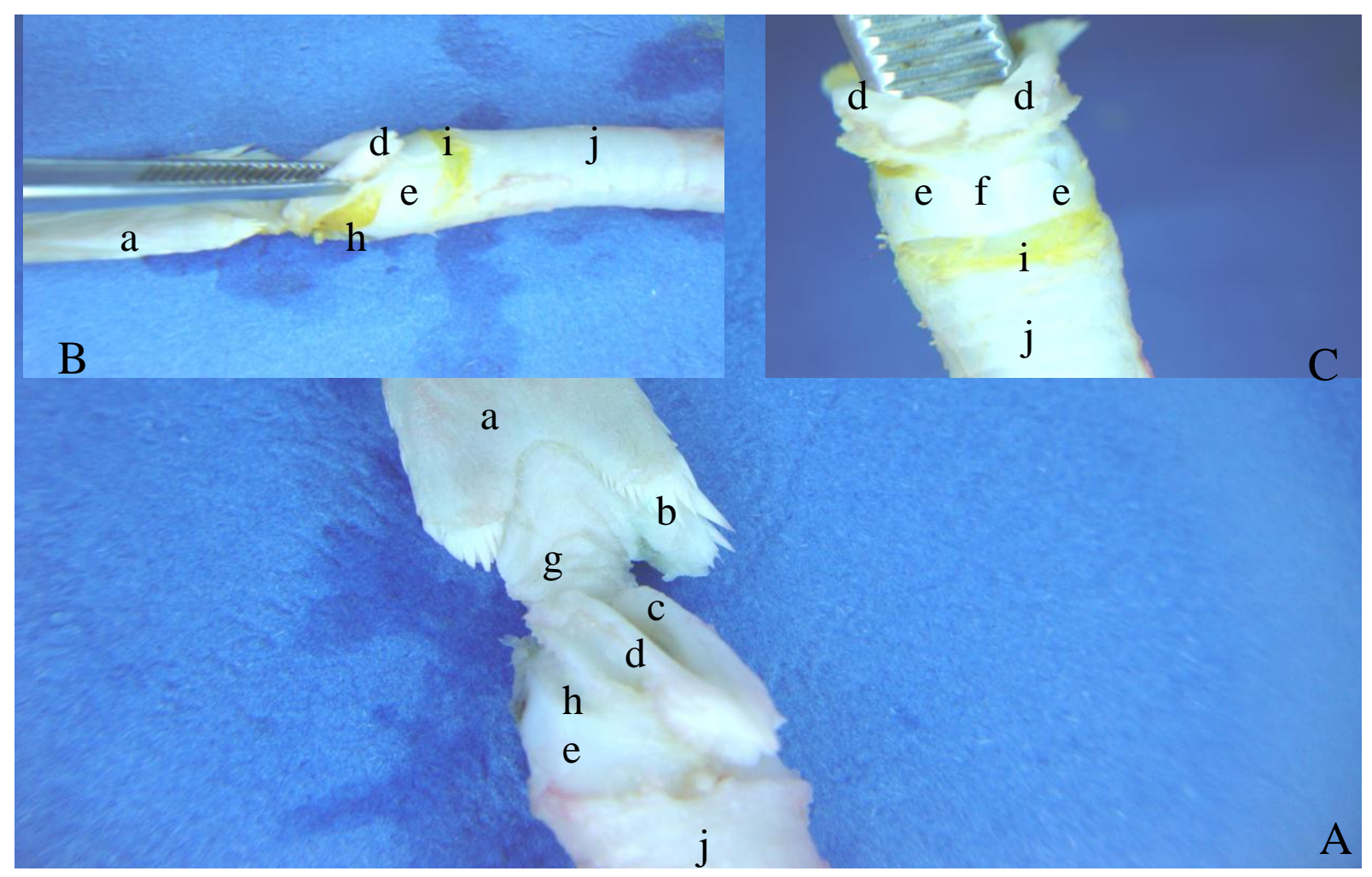

Fig. (7): Laryngeal cartilages (coloured by watery yellow colour) of the Turkey (lateral (A,B), and caudal (C) view) demonstrating: tongue (a), lingual papillae (b), laryngeal glottis (c), arytenoid cartilages (d), cricoid wings (e), procricoid cartilage (f), arytenoglossal ligament (g), arteno-cricoid ligament (h), crico-traceal ligament (i), proximal trachea $(\mathrm{j})$.

\section{Discussion}

The laryngeal mound appeared as heart-shaped rostrocaudally in direction. These results were fully confirmed to the finding $(4,5,6)$ in the chicken, turkey, and long-legged buzzard, where as uncorresponding with, (11) who said the laryngeal mound relatively elongated lozenge-shape in duck and goose, and (7) who portrayed the laryngeal mound as roughly triangular in shape in the west african guinea fowl.The laryngeal inlet (glottis) appeared as slit-like opening, limited by laryngeal arytenoid cartilages, it was continuous caudally by the laryngeal fissure, these consequences agreed with (6, 9) in domestic fowl. While $(7,8,14)$ elucidated that the laryngeal fissure seemed as an inverted triangular shape in the West African guinea fowl and ostriches. The laryngeal glottis can be thought of as a valve atop the lungs which can prevent air flow out of the lungs (as when holding your breath) or the inward flow of foreign matter like food or water into the lungs. $(4,8,15,16)$. The mean length of glottis in the turkey (1.15 $0.05 \mathrm{~cm})$ this result corresponded with (11) who explained that the length of the glottis in a typical male chicken was about (1.1 $\mathrm{cm})$, and uncoincided with $(1.5 \mathrm{~cm}) \mathrm{him}$ in turkey and $(1.3 \mathrm{~cm})$ in duck and goose, Kabak, et al., (6) referred to the length of the glottis was $(0.9 \mathrm{~cm})$ in long legged buzzard, and Tadjalli, et. al, (8) showed the glottis in the ostriches was very large and the mean length of it was $(3.33 \pm 0.75$ $\mathrm{cm})$. The width of the glottis was relatively small $(0.22 \pm 0.00 \mathrm{~cm})$; this outcome was very close to long legged buzzard where was the width of the glottis $(0.186 \mathrm{~cm})(6)$. But in the ostriches was very wide (8), this consequence disagreement with (11) who 
said the width of glottis were $(0.5 \mathrm{~cm}),(0.3$ $\mathrm{cm})$, and $(0.4 \mathrm{~cm})$ in turkey, duck, and goose respectively.The laryngeal papillae which protruded in the caudal part of the laryngeal mound and had not the sagittal rows of the inlet, these consequences harmonized with $(4,11)$ in turkey, and disagreement with $(4,6,11)$ who clarified that there were, in the chicken and long legged buzzard, two sagittal rows of 5-6 small papillae run parallel with the rims of the inlet and dorsal furrow. While (8) said the papillae were not visualized on the larynx in ostriches. The laryngeal papillae assisted in the ingestion of solid particles and important in swallowing to rake food caudally into the esophagus by quickly movements (4, 15).Cricoid cartilage was single hyaline cartilage consist of, body which cesspool-like plate, and the left and right wings, these consequences harmonized with $(5,11,13)$ they observe similar results in the domestic fowl, duck, and Spheniscidae, and un corresponding with, Baumel, et al., (9) referred to, the body and the rostral process of the cricoid cartilage were incomplete in the columba and corvus. McLelland (4), Baumel, et al., (9) said the cricoid wings were separated as dorsal cricoid cartilages, and rod like cartilages in songbirds, Corvus corax, $C$. orru, and C. brachyrhynchos.Procricoid cartilage was unpaired, hyaline cartilage type, and it was a median short-tackshaped cartilage at the caudal portion of the larynx, consisted of body dorsally and tail ventrally. These results in agreement with $(6,9,11)$ in chicken, turkey, Columba, and long-legged buzzard, while disagreement with, (8), in ostriches where had not procricoid cartilage, and (9) noticed the procricoid body was cuboidal or spherical shape and the tail was absent in Corvus.Arytenoid cartilages were paired hyaline cartilages on the left and right walls of the larynx which met together dorsocaudally, consisted of body, rostral process, and caudal process. These results agreed with $(4,6,9,11)$ in chicken, duck, turkey and long-legged buzzard, and disagreed with, (9) said the arytenoid caudal process absent in ratites and penguins, and with (8) noticed the arytenoid cartilages consisted of three extended processes caudolaterally which were rostral (elongated), middle (circular) and caudal (hemisphere) processes in the ostriches. In this study, the synovial joining between arytenoid cartilages and other laryngeal cartilages, attributable to allow highly free movements by intrinsic laryngeal muscles (6).Superficial intrinsic laryngeal muscles were paired attached with cricoid and arytenoid cartilages. They acted as the dilator of the laryngeal glottis when contracted by abduct of arytenoid cartilages. (6, 9, 11) Deep intrinsic laryngeal muscles were paired lie under the precedent muscles composed of three parts medial, middle, and lateral attached with cricoid and arytenoid cartilages. These muscles acted as constrictor of the laryngeal glottis when contracted by adduct of the arytenoid cartilages, $(6,9,11)$ in chicken, Gallus, Corvus brachyrhynchos, and long-legged buzzard, and uncoincided with (9) found the constrictor muscles composed of five discrete muscles in Columba and Corvus speciesRostral extrinsic laryngeal muscles were paired, attached with cricoid body, and rostral basibranchial bone of the hyoid bone, these outcomes fully confirmed with $(9,11)$ in chicken and Columba livia.The caudolateral and caudomedial extrinsic laryngeal muscles were paired arise mainly from sternotrachealis muscle these result disagree with $(9,11)$ they found these muscles arise from composite tracheal muscle in chicken and Columba livia.Laryngeal ligaments were represented by four types, the right and left arytenocricoid ligaments where connected between body of arytenoid cartilage and wing of cricoid cartilages. This result inconsistence with $(9,11)$ in non-passerine (spheniscids, Gallus, Columba, and stix), this ligament linked between rostral process, body of arytenoid cartilage, and body and wings of cricoid cartilage, Baumel, et al., (9) said, in Corvids (passerine species), this ligament named the same ligament as aryteno-cricoid dorsalis ligament which continued 
caudally between arytenoid body and the dorsal cricoid cartilage in Corvids (passerine species), while Getty , (11) named, this ligament named as the caudal crico-arytenoid ligament in chicken. Aryteno-arytenoid ligament was small ligament connected the right and left arytenoid cartilages at the caudal midline dorsal to the procricoarytenoid synovial joints, this ligament occurred in chicken and Corvus brachyrhynchos but connected at body and caudal process of arytenoid cartilage $(9,11)$. Aryteno-glossal ligament was thick ligament attached the rostral processes and the paraglossal bone of the tongue this outcome agree with $(9,11)$ in Gallus and Columba livia.

\section{References}

1. Reece, W.O. (2005): Avian respiratory system morphology. In: Function Anatomy and Physiology of Domestic Animals $3^{\text {rd }}$ (ed.): Lippincott Williams and Wilking. PP. 230-268

2. Nash, H. (2007): Respiratory System of Birds: Anatomy and Physiology. Pet edu. Com Drs. Foster \& Smiths source for expert pet information

3. Pesek, L. (2000): The avian respiratory system. Winged Wisdom Pet Bird Magazine 1: 1-3

4. McLelland, J., (1990): A Color Atlas of Avian Anatomy. Wolfe Publishing Ltd. Eng. PP. 95-119

5. Bacha, W.J., and Bacha, L.M. (2000): Color Atlas of Veterinary Histology 2nd (ed.): Lippincott Williams \& Wilkins. PP: 175-190

6. Kabak, M., Orhan, I.O., and Haziroglu, R.M. (2007): The gross anatomy of larynx, trachea, and syrinx in the Long-Legged Buzzard (Buteo rufinus). Ana. Histo. Ember. 36 (1): 27-32.

7. Lbe, C.S., Onyeanusi, B.I., Salami, S.O., Umosen, A.D., and Maidawa, S.M. (2008): Studies of the major respiratory pathways of the West African guinea fowl (Numida meleagris galeata): The Morphometric and Macroscopic Aspects. Inter. J. of Poul. Sci. 7 (10): 997-1000

8. Tadjalli, M., Mansouri, S. H., and Poostpasand, A. (2008): Gross anatomy of the oropharyngeal cavity in the ostrich (Struthio camelus). Iranian J. of Vet.
Resear. Shiraz Univ. 9 (4): 316322

9. Baumel, J.J., King, A.S., Breazile, J.E., Evans, H.E., and Vandan Berge, J.C. (1993): Respiratory system. In: Hand book of Avian Anatomy Nomina Anatomica Avium $2^{\text {nd }}$ ed: Club. Cambridge, Massachusetts. PP: 257-299

10. Swenson, M.J. (2004): Ducks Physiology of Domestic Animals. $9^{\text {th }}$ ed: Darya. Garya. Ganj. New Delhi. PP: 203

11. Getty, R. (1975): Anatomy of domestic animals. W.S. Saunders Co. Philadelphia. PP: 1884-1917

12. Hogg, D.A. (1982): Ossification of the laryngeal, tracheal and syringeal cartilages in the domestic fowl. $J$. Anat. 134 (1): 57-71

13. Brown, R.E., Brain, J.D., and Wang, N. (1997): The avian respiratory system: A unique model for studies of respiratory toxicosis and for monitoring air quality. Environ Health Perspect (105):188-200

14. Frandson, R.D., Wilke, W.L., and Fails, A.D. (2009): Anatomy and Physiology of Farm Animals $7^{\text {th }}$ ed : Wiley-Black Well. PP. 471474

15. Fitch, W.T.S. (1994): Vocal Tract Length Perception and the Evolution of Language. $\mathrm{PhD}$. Thesis. Brown Uni. B.A. Biol. PP. $1-95$

16. Smallwood, J.E. (2010): Selected topics in avian anatomy. Wildlife Rehabilitators of North Carolina. PP: 1-24 


\section{الخلاصة}

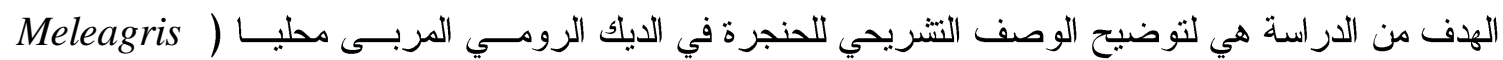
و gallopava

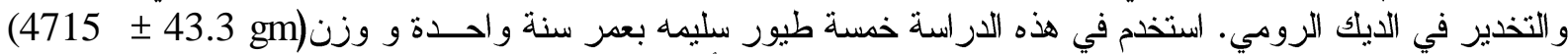

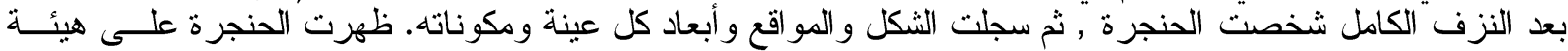

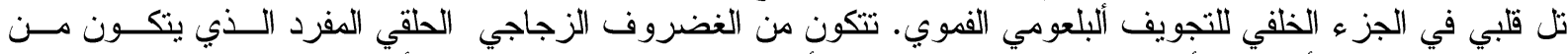

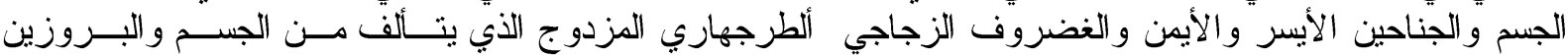

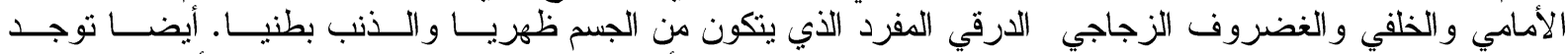
العضلآت الحنجرية الهيكلية الداخلية اللسطحية والغائرة والخارجية الأمامية و والخلفية وحشية و الخلفية ألإنسية. 